\title{
Outcomes consequent to "early" COPD for interventional studies
}

To the Editor:

The recent paper by ÇOLAK et al. [1] and colleagues adds to the growing body of information relating to early COPD. The study confirms the importance of symptoms among individuals prior to meeting the arbitrary threshold of forced expiratory volume in $1 \mathrm{~s}\left(\mathrm{FEV}_{1}\right)$ to forced vital capacity ratio $<0.7$, and that these individuals are at risk for serious morbidity and mortality. Importantly, this is demonstrated in a population-based sample. The authors clearly address the difficulty in distinguishing "early" from "mild" COPD, but have included younger individuals, which suggests that "early" disease is present in many. Recognition of this group at serious risk for subsequent events invites consideration of interventions designed to alter the disease course. To date, attempts to alter natural history of COPD have been powered on changes in airflow assessed by $\mathrm{FEV}_{1}$. Alternative outcomes could be very useful: could Çolak and colleagues estimate the sample sizes for interventional studies designed to alter the course of COPD using the outcomes they assessed?

@ERSpublications

Data presented in the recent study by Colak and co-workers permit estimates of trials to alter natural history of COPD using endpoints other than FEV $_{1}$ http://bit.ly/2sIxMSB

Cite this article as: Rennard SI. Outcomes consequent to "early" COPD for interventional studies. Eur Respir J 2020; 55: 1902380 [https://doi.org/10.1183/13993003.02380-2019].

Stephen I. Rennard

Division of Pulmonary, Critical Care, Allergy and Sleep Medicine, Dept of Internal Medicine, University of Nebraska Medical Center, Omaha, NE, USA.

Correspondence: Division of Pulmonary, Critical Care, Allergy and Sleep Medicine, Dept of Internal Medicine, University of Nebraska Medical Center, Omaha, NE, USA. E-mail: srennard@unmc.edu

Received: 11 Dec 2019 | Accepted: 15 Dec 2019

Conflict of interest: S.I. Rennard was an employee of AstraZeneca until 30 November, 2019 and holds shares in the company; and has received funding from the tobacco industry for studies relating to harm reduction and to the impact of tobacco smoke on stem cells; he also consulted with RJ Reynolds without personal fee on the topic of harm reduction; he received funding from RJ Reynolds to evaluate the effect of a harm reduction product in normal smokers (1996) and in subjects with chronic bronchitis (1999) and to assess the effect of smoking cessation on lower respiratory tract inflammation (2000); he participated in a Philip Morris multicentre study to assess biomarkers of smoke exposure (2002); he received funding for a clinical trial from the Institute for Science and Health (2005), which receives support from the tobacco industry, to evaluate biomarkers in exhaled breath associated with smoking cessation and reduction; this study was supplemented with funding from Lorillard and RJ Reynolds; he received a grant from the Philip Morris External Research Program (2005) to assess the impact of cigarette smoking on circulating stem cells in the mouse; he consulted with RJ Reynolds on the topic of harm reduction until 2007, but did not receive personal remuneration for this. There are no active tobacco-industry funded projects. All ties with tobacco industry companies and entities supported by tobacco companies were terminated in 2007.

\section{Reference}

1 Çolak Y, Nordestgaard BG, Vestbo J, et al. Prognostic significance of chronic respiratory symptoms in individuals with normal spirometry. Eur Respir J 2019; 54: 1900734. 
(D)

\section{CrossMark}

From the authors:

We thank S.I. Rennard for the interest in our study. We observed that individuals with chronic respiratory symptoms and normal spirometry had an increased risk of hospitalisations and death due to respiratory disease [1]. S.I. Rennard was particularly interested in estimating the sample size required for an intervention trial in individuals with early COPD based on the outcomes used in our study. Since COPD develops gradually over many years [2], identification of younger adults at high risk of developing COPD could lead to implementation of preventive measures before disease onset and thereby halt progression to improve long-term prognosis [3-5]. However, attempts to alter the natural history of COPD have mainly focused on lung function decline and development of chronic airflow limitation, rather than clinical outcomes such as respiratory hospitalisations or death.

Recently, an operational definition of early COPD has been proposed by an international group of experts [6]. Accordingly, early COPD could be defined as age $<50$ years with $\geqslant 10$ pack-years of tobacco consumption with one or more of the following: 1$)$ forced expiratory volume in $1 \mathrm{~s}\left(\mathrm{FEV}_{1}\right) /$ forced vital capacity (FVC) less than the lower limit of normal (LLN); 2) compatible computed tomography abnormalities, i.e. visual emphysema, air trapping or bronchial thickening graded mild or worse; and/or 3) evidence of accelerated $\mathrm{FEV}_{1}$ decline of $\geqslant 60 \mathrm{~mL}$ per year. In a newly published study, we found that $15 \%$ of individuals aged $<50$ years with $\geqslant 10$ pack-years of tobacco consumption fulfil criteria of early COPD in Copenhagen General Population Study [7].
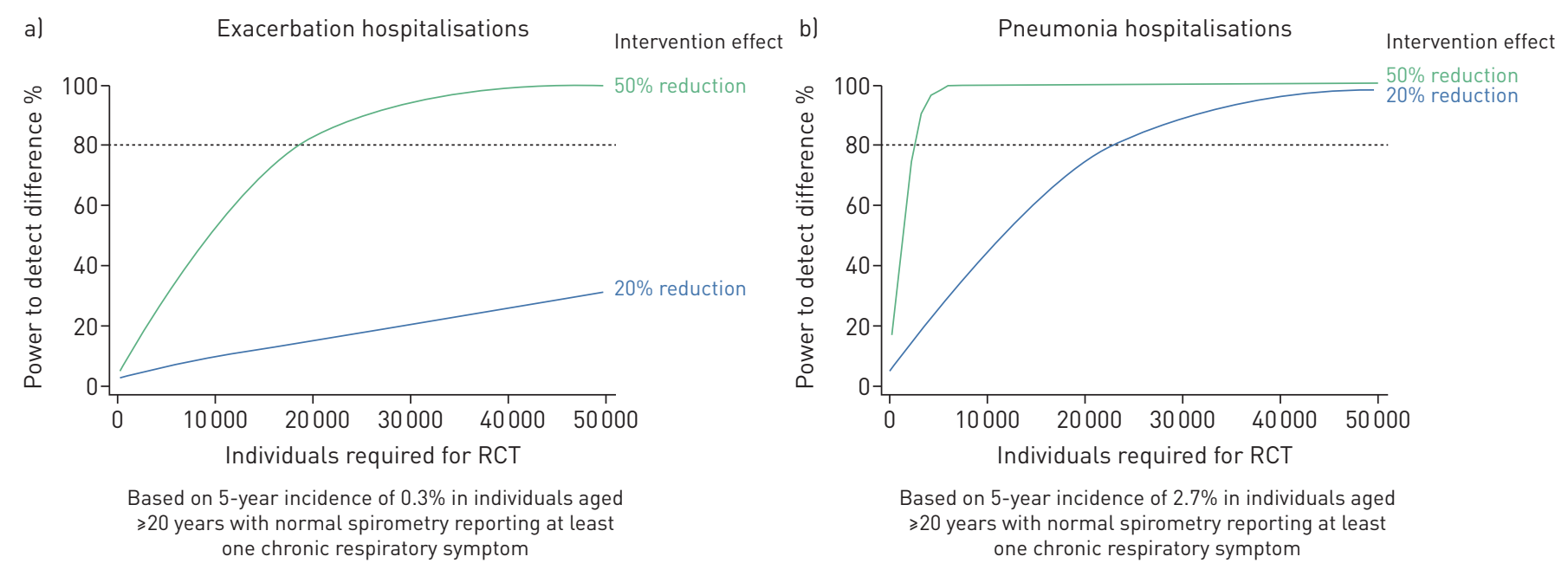

Based on 5 -year incidence of $0.3 \%$ in individuals aged
$\geqslant 20$ years with normal spirometry reporting at least one chronic respiratory symptom

-year incidence of $27 \%$ in individuals aged one chronic respiratory symptom

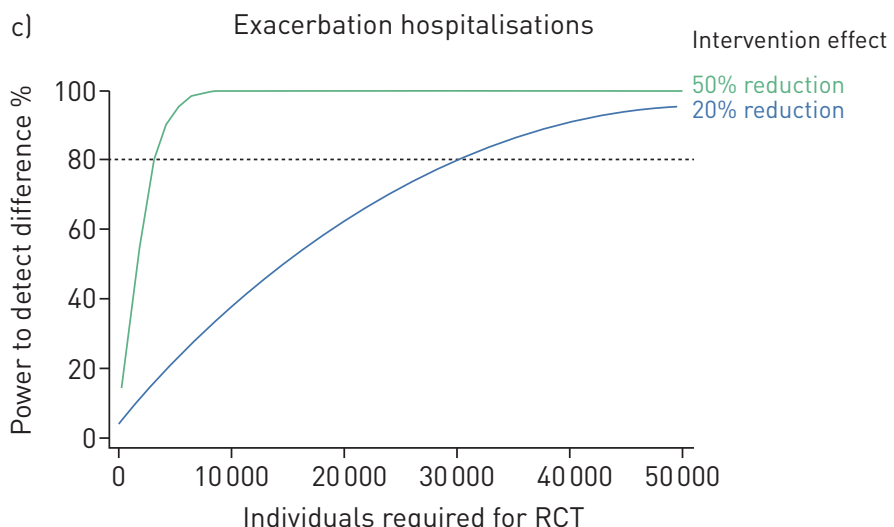

Based on 5-year incidence of $2.1 \%$ in individuals aged 20-50 years with $\mathrm{FEV}_{1} / \mathrm{FVC}<\mathrm{LLN}$ and smoking history $\geqslant 10$ pack-years

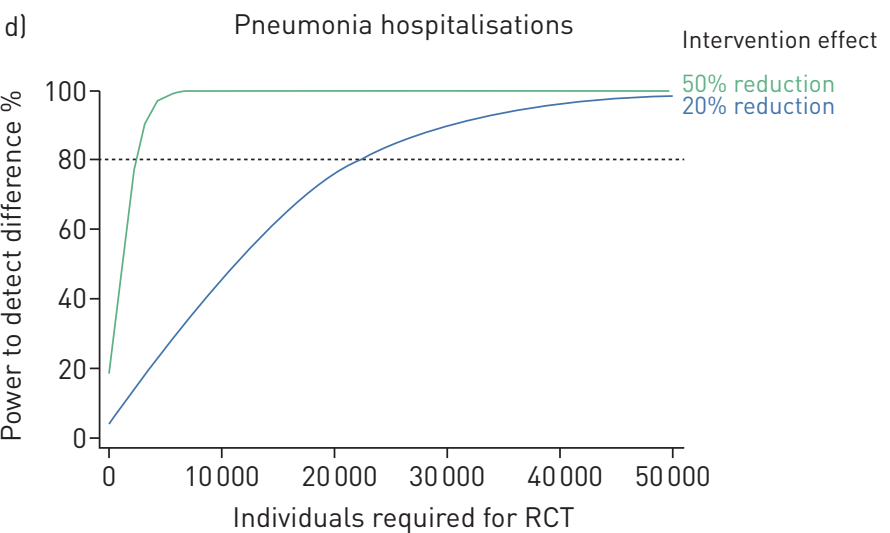

Based on 5 -year incidence of $2.8 \%$ in individuals aged 20-50 years with $\mathrm{FEV}_{1} / \mathrm{FVC}<\mathrm{LLN}$ and smoking history $\geqslant 10$ pack-years

FIGURE 1 Estimating sample size for an intervention trial against COPD-related clinical outcomes. Power calculation are based on 5-year incidence of hospitalisations due to exacerbation of obstructive lung disease and pneumonia in a, b) individuals aged $\geqslant 20$ years with normal spirometry defined as forced expiratory volume in $1 \mathrm{~s}\left(\mathrm{FEV}_{1}\right) /$ forced vital capacity (FVC) $\geqslant 0.70$ reporting at least one chronic respiratory symptom in form of dyspnoea, chronic mucus hypersecretion, wheezing, and cough, and $\mathrm{c}$, d) in individuals aged $20-50$ years with FEV 1 /FVC less than the lower limit of normal (LLN) and smoking history $\geqslant 10$ pack-years. RCT: randomised controlled trial. 
Individuals defined with early COPD more often had chronic respiratory symptoms and an increased risk of acute respiratory hospitalisations and early death.

To determine the sample size required for an intervention trial, we need assumptions on incidence of outcomes and expected intervention effects. Thus, based on our data, we investigated statistical power in two hypothetical populations, i.e. 1) individuals aged $\geqslant 20$ years with normal spirometry reporting at least one chronic respiratory symptom in form of dyspnoea, chronic mucus hypersecretion, wheezing, and cough, and 2) individuals aged $20-50$ years with $\mathrm{FEV}_{1} / \mathrm{FVC}<\mathrm{LLN}$ and smoking history $\geqslant 10$ pack-years. For the expected intervention effect, we chose a $50 \%$ or $20 \%$ reduction in hospitalisations due to exacerbation of obstructive lung disease and pneumonia over a 5-year invention period. We estimated sample sizes based on $80 \%$ power, two-sided p-value $<0.05$, and 5 -year incidence rates for the outcomes observed for the two hypothetical populations.

In individuals aged $\geqslant 20$ years with normal spirometry reporting at least one chronic respiratory symptom, expected intervention reductions of respectively $50 \%$ and $20 \%$ would require 18700 and $>50000$ individuals for exacerbation hospitalisations and 2400 and 23200 individuals for pneumonia hospitalisations in an intervention trial (figure 1b). Correspondingly, in individuals aged 20-50 years with $\mathrm{FEV}_{1} / \mathrm{FVC}<\mathrm{LLN}$ and smoking history $\geqslant 10$ pack-years, 3100 and 29700 individuals for exacerbation hospitalisations and 2300 and 22500 individuals for pneumonia hospitalisations would be required in an intervention trial, respectively (figure 1c). We also investigated all-cause mortality in both studies, an unspecific outcome for COPD. For the two designs, sample sizes of 16300 individuals and 46400 would be required for $80 \%$ power assuming a $20 \%$ effect size; however, it is difficult to imagine interventions, other than smoking cessation, that could reduce mortality in these scenarios.

We hope that the provided sample size estimation in different interventional settings against important COPD-related outcomes in susceptible individuals at risk of developing COPD later in life and/or have early COPD can be useful. However, with the number of individuals required in an intervention trial, the clinical utility may be limited.

\section{@ERSpublications}

Power calculations for outcomes consequent to early COPD http://bit.ly/30MrvCd

Cite this article as: Çolak Y, Nordestgaard BG, Vestbo J, et al. Outcomes consequent to "early" COPD for interventional studies. Eur Respir J 2020; 55: 2000073 [https://doi.org/10.1183/13993003.00073-2020].

Yunus Çolak ${ }^{1,2,3}$, Børge G. Nordestgaard ${ }^{1,2,3}$, Jørgen Vestbo $\oplus^{4}$, Peter Lange ${ }^{2,3,5,6}$ and Shoaib Afzal ${ }^{1,2,3}$

${ }^{1}$ Dept of Clinical Biochemistry, Herlev and Gentofte Hospital, Copenhagen University Hospital, Herlev, Denmark. ${ }^{2}$ The Copenhagen General Population Study, Herlev and Gentofte Hospital, Copenhagen University Hospital, Herlev, Denmark. ${ }^{3}$ Faculty of Health and Medical Sciences, University of Copenhagen, Copenhagen, Denmark. ${ }^{4}$ Division of Infection, Immunity and Respiratory Medicine, School of Biological Sciences, Manchester Academic Health Science Centre, University of Manchester and Manchester University NHS Foundation Trust, Manchester, UK. ${ }^{5}$ Section of Epidemiology, Dept of Public Health, University of Copenhagen, Copenhagen, Denmark. ${ }^{6}$ Section of Respiratory Medicine, Dept of Internal Medicine, Herlev and Gentofte Hospital, Copenhagen University Hospital, Herlev, Denmark.

Correspondence: Shoaib Afzal, Dept of Clinical Biochemistry and the Copenhagen General Population Study, Herlev and Gentofte Hospital, Copenhagen University Hospital, Herlev Ringvej 75, 2730 Herlev, Denmark.

E-mail: shoaib.afzal@regionh.dk

Received: 13 Jan 2020 | Accepted: 14 Jan 2020

Conflict of interest: Y. Çolak reports personal fees from Boehringer Ingelheim and AstraZeneca, outside the submitted work. B.G. Nordestgaard has nothing to disclose. J. Vestbo reports personal fees for consultancy from GlaxoSmithKline, Chiesi Pharmaceuticals, Boehringer Ingelheim, Novartis, Almirall, AstraZeneca and Bioxydyn, personal fees for lectures from GlaxoSmithKline, Chiesi Pharmaceuticals, Novartis, AstraZeneca and Boehringer Ingelheim, outside the submitted work. P. Lange reports grants and personal fees from Almirall, Boehringer Ingelheim and GSK, personal fees from AstraZeneca, Novartis, Nycomed, Pfizer and Mundipharma, outside the submitted work. S. Afzal has nothing to disclose.

\section{References}

1 Çolak Y, Nordestgaard BG, Vestbo J, et al. Prognostic significance of chronic respiratory symptoms in individuals with normal spirometry. Eur Respir J 2019; 54: 1900734.

2 Lange P, Celli B, Agusti A, et al. Lung-function trajectories leading to chronic obstructive pulmonary disease. N Engl J Med 2015; 373: 111-122.

3 Rennard SI, Drummond MB. Early chronic obstructive pulmonary disease: definition, assessment, and prevention. Lancet 2015; 385: 1778-1788.

4 Soriano JB, Polverino F, Cosio BG. What is early COPD and why is it important? Eur Respir J 2018; 52: 1801448. 
5 Soriano JB, Zielinski J, Price D. Screening for and early detection of chronic obstructive pulmonary disease. Lancet 2009; 374: 721-732.

6 Martinez FJ, Han MK, Allinson JP, et al. At the root: defining and halting progression of early chronic obstructive pulmonary disease. Am J Respir Crit Care Med 2018; 197: 1540-1551.

7 Çolak Y, Afzal S, Nordestgaard BG, et al. Prevalence, characteristics, and prognosis of early COPD: the Copenhagen General Population Study. Am J Respir Crit Care Med 2019; in press [https://doi.org/10.1164/rccm. 201908-1644OC].

Copyright $\odot$ ERS 2020 